\title{
SISTEMA ANTIOXIDANTE ENVOLVENDO O CICLO METABÓLICO DA GLUTATIONA ASSOCIADO A MÉTODOS ELETROANALÍTICOS NA AVALIAÇÃO DO ESTRESSE OXIDATIVO
}

\author{
Laércio Rover Júnior, Nelci Fenalti Höehr* e Adriana Paula Vellasco \\ Faculdade de Ciências Médicas, UNICAMP, CP 6111, 13083-970 Campinas - SP \\ Lauro Tatsuo Kubota \\ Instituto de Química, UNICAMP, CP 6154, 13083-970 Campinas - SP
}

Recebido em 27/1/00; aceito em 12/5/00

\begin{abstract}
ANTIOXIDANT SYSTEM INVOLVING THE GLUTATHIONE METABOLIC CYCLE ASSOCIATED TO ELECTROANALYTICAL METHODS IN THE OXIDATIVE STRESS EVALUATION. The most relevant advances on the analytical applications of glutathione determination based on glutathione redox cycle and the antioxidant system are given. The main enzymes that participate of the glutathione metabolism are the glutathione peroxidase and glutathione reductase. The glutathione peroxidase has a major role in the removal of hydrogen peroxide and lipid peroxides from the cells. These enzymes, operating in tandem with catalase and superoxide dismutase promote a scavenging of oxyradical products in tissues minimizing damages caused by these species. Reduced glutathione is the major intracellular thiol found in mammals and changes in the glutathione concentration in biological fluids or tissues may provide a useful marker in certain disorders like hemolytic anemia, myocardial oxidative stress and in the investigation of some kinds of cancers. Particular attention is devoted to the main advantages supplied by biosensors in which there is an incorporation of bioactive materials for the glutathione determination. The correlation between stability and sensitivity of some reduced glutathione electrochemical sensors is discussed.
\end{abstract}

Keywords: glutathione; electroanalysis; bioelectrochemistry; oxidative stress.

\section{INTRODUÇÃO}

A incidência de doenças relacionadas a processos cancerígenos no organismo, envolvendo a formação de espécies reativas de oxigênio tais como peróxido de hidrogênio e o radical hidroxila, vem merecendo especial atenção nos últimos anos. Existe uma importante correlação entre os níveis de glutationa em sua forma reduzida e os mecanismos enzimáticos de defesa. Esta observação tem promovido uma série de estudos clínicos sobre a interdependência entre o aumento dos níveis de glutationa no plasma sangüíneo e doenças cancerígenas em determinados órgãos vitais como rins e pulmões ${ }^{1,2}$.

Glutationa, um tripeptídeo ( $\gamma$-L-glutamil-L-cisteinil-glicina), existe no organismo em suas formas reduzida (GSH) e oxidada (GSSG), atuando direta ou indiretamente em muitos processos biológicos importantes, incluindo a síntese de proteínas, metabolismo e proteção celular ${ }^{3}$. Em particular, problemas na síntese e metabolismo da glutationa estão associados a algumas doenças, nas quais os níveis de glutationa e das enzimas que atuam no seu metabolismo podem ser bastante significativos no diagnóstico de alguns tipos de câncer, bem como em outras doenças relacionadas ao estresse oxidativo ${ }^{4-6}$.

Mudanças na concentração deste tripeptídeo podem ser um indicador útil em certas desordens fisiológicas como anemias causadas por infecção ou seguidas pela administração de algumas drogas oxidantes ${ }^{7}$, no monitoramento da eficácia de alguns tratamentos usando N-acetil-L-cisteína (NAC) durante o metabolismo do paracetamol ${ }^{8}$, no tratamento de pacientes com artrite reumatróide ${ }^{9}$ e na investigação do estresse oxidativo do miocárdio ${ }^{10}$. Há alguns anos, foi reportado o abaixamento dos níveis de GSH em hemácias e plasma de pessoas infectadas com o vírus da imunodeficiência (HIV-1) associado à síndrome da imunodeficiência adquirida (AIDS). Os autores ${ }^{11}$ sugerem

\footnotetext{
* E-mail: nelci@fcm.unicamp.br
}

que a diminuição observada nos níveis de GSH correlacionavase com a progressão da AIDS devido ao tratamento com drogas oxidantes como o NAC, inibindo a replicação do vírus.

As membranas celulares e intracelulares, que possuem grandes quantidades de ácidos graxos polinsaturados, são um importante alvo para o ataque de radicais livres. Espécies radicalares provenientes do oxigênio podem estar envolvidas em processos patológicos ou associadas com exercícios físicos prolongados, causando um estresse oxidativo dos fosfolipídeos, proteínas e ácido desoxirribonuclêico (DNA) das membranas celulares ${ }^{5,6}$. Assim, um importante sistema de defesa enzimático contra o aumento de radicais livres, envolve a enzima glutationa peroxidase $^{12}$ (GSH-Px), encontrada em muitos tecidos de origem animal. Em trabalhos recentes ${ }^{13-15}$ foram reportadas as determinações dos principais parâmetros cinéticos de GSH-Px, propondo mecanismos catalíticos de funcionamento desta enzima envolvendo seus principais substratos, glutationa e peróxido de hidrogênio. Quatro diferentes tipos de glutationa peroxidases são conhecidas, dentre as quais a fosfolipídeo hidroperóxido glutationa peroxidase (PHGSH-Px) também consegue promover a redução de hidroperóxidos a partir de complexos lipídicos como colesterol, mesmo quando os peróxidos estão presentes na membrana celular ${ }^{15}$.

Glutationa peroxidase, descrita inicialmente por Mills ${ }^{16} \mathrm{em}$ 1957, não tem sido encontrada em plantas superiores ou bactérias. A atividade enzimática de GSH-Px é um dos meios de controle do organismo dos níveis de peróxido de hidrogênio e hidroperóxidos lipídicos, oriundos do ataque de espécies radicalares ${ }^{3,17}$. A enzima glutationa peroxidase possui uma característica importante, apresentando um resíduo de cisteína contendo selênio covalentemente ligado ao restante da enzima. O selênio foi caracterizado como um componente essencial da enzima $^{18}$ em 1973 e a forma do selênio na enzima, presente em fígado de rato, foi identificada em 1978 como uma selenocisteína ${ }^{19}$. A deficiência de selênio no organismo, um nutriente essencial, apresenta uma diminuição na atividade 
desta enzima em sua forma reduzida, e tem sido associada com alterações no metabolismo celular ${ }^{20,21}$. Em um trabalho recente ${ }^{22}$, foi determinada a distribuição de selênio em plasma humano por cromatografia líquida, onde as maiores frações deste elemento encontram-se associadas junto à enzima GSH-Px e albumina. Neste sentido, um controle dos níveis de glutationa (GSH) torna-se importante, já que níveis normais de GSH em células de mamíferos ${ }^{3}$ estão na faixa de 0,5 a $10 \mathrm{mmol} \mathrm{L}^{-1}$.

Outra enzima que age conjuntamente com a glutationa peroxidase é a enzima glutationa redutase $e^{3}$ (GR). Esta enzima não age diretamente na remoção de espécies radicalares, porém é responsável pela regeneração da glutationa à sua forma reduzida $(\mathrm{GSH})$ na presença de nicotinamida adenina dinucleotídeo fosfato (NADPH), tendo como objetivo impedir a paralisação do ciclo metabólico da glutationa ${ }^{3}$ (Figura 1). Assim, alguns trabalhos têm sido desenvolvidos para determinação destas enzimas tanto em tecidos celulares como no plasma sangüíneo ${ }^{23-26}$.

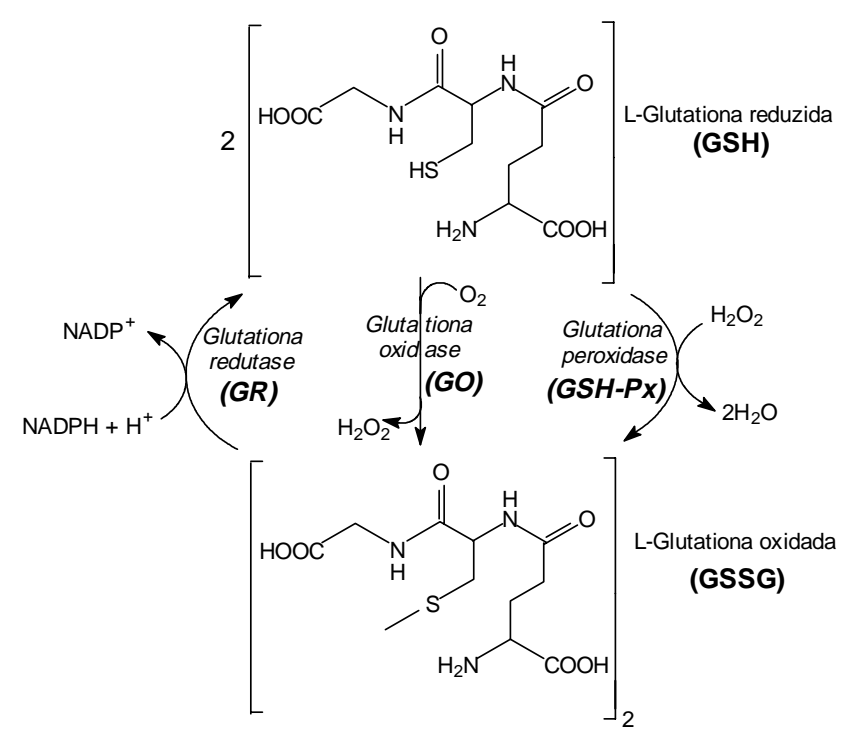

Figura 1. Interconversão de glutationa nas suas formas reduzida (GSH) e oxidada (GSSG) pela ação das enzimas glutationa peroxidase $(G S H-P x)$, glutationa oxidase $(G O)$ e glutationa redutase $(G R)^{3}$.

\section{SISTEMAS DE DEFESA ANTIOXIDANTE}

Glutationa e as enzimas que fazem parte do ciclo catalítico deste peptídeo, apresentam associações com alterações dos estados antioxidantes e com o aumento do estresse oxidativo. Estas alterações implicam em lesões de DNA gerando processos pré-mutagênicos e podendo levar, em alguns casos, ao câncer $^{27-30}$. Desta forma, a quantificação de glutationa pode indicar uma possível correlação entre a diminuição das atividades de enzimas antioxidantes, como a glutationa peroxidase, e o aumento nos níveis de bases de DNA lesadas devido ao dano oxidativo, comprovando a hipótese de que reações que levam à formação de radicais livres podem aumentar a quantidade de células malignas ${ }^{31,32}$.

A presença de radicais livres têm sido correlacionada com um grande número de doenças, indicando que estas espécies não têm um papel etiológico na grande maioria dos estados patológicos, mas que participam diretamente dos mecanismos fisiopatológicos que determinam a continuidade e as complicações presentes nestes processos ${ }^{33}$.

As espécies radicalares estão envolvidas nos mecanismos de reações inflamatórias ou atuam como segundos mensageiros para manter diversas funções celulares ${ }^{34,35}$. Assim, o equilíbrio entre a formação e a remoção de espécies radicalares no organismo deve ser regulado de forma que as reações e processos metabó- licos dependentes das mesmas possam ocorrer em um nível adequado para a manutenção da fisiologia das células ${ }^{36}$.

$\mathrm{O}$ desequilíbrio entre a formação e a remoção dos radicais livres no organismo, decorrente da diminuição dos antioxidantes endógenos ou do aumento da geração de espécies oxidantes, gera um estado pró-oxidante que favorece a ocorrência de lesões oxidativas em macromoléculas e estruturas celulares, inclusive podendo resultar na morte celular ${ }^{33,36}$. Este tipo de lesão oxidativa é definida como estresse oxidativo, que segundo $\mathrm{Sies}^{37}$, designa uma condição na qual ocorre um desequilíbrio entre as concentrações de espécies pró e antioxidantes.

Em muitas doenças a natureza da espécie radicalar que amplifica a lesão primária não é conhecida. Desta forma, torna-se difícil o planejamento correto da utilização de fármacos com propriedades antioxidantes que eliminem diretamente o radical livre, impedindo sua reação com alvos celulares ou interrompendo as cadeias radicalares e assim, evitando a propagação das lesões provocadas por esses radicais ${ }^{38}$. O emprego adequado destes fármacos e das estratégias terapêuticas dependem de diversos fatores, tais como: entendimento dos processos dependentes dos radicais livres envolvidos na fisiopatologia de diversas doenças, identificação das fontes celulares geradoras das espécies radicalares potencialmente tóxicas, identificação dos compostos que possam atuar como antioxidantes, bem como a sua distribuição nos tecidos, localização subcelular e mecanismo de ação ${ }^{33,38}$.

Neste contexto, os dois principais meios de defesa antioxidantes no organismo podem ser divididos em dois grupos, enzimáticos e não enzimáticos. Os sistemas enzimáticos envolvem as enzimas do ciclo redox da glutationa, particularmente a glutationa peroxidase. Estudos demonstraram também que outras enzimas antioxidantes, como glutationa redutase e glicose-6-fosfato-dehidrogenase, apresentaram propriedades protetoras similares à glutationa peroxidase ${ }^{27,39}$. Outros sistemas enzimáticos de defesa antioxidantes operando em conjunto com as enzimas citadas anteriormente incluem a superóxido

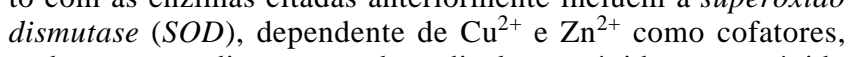
onde ocorre a dismutação do radical superóxido em peróxido de hidrogênio e oxigênio (Eq. 1), bem como a catalase, que converte peróxido de hidrogênio em água e oxigênio molecular nas hemácias ${ }^{3}$ (Eq. 2):

$2 \mathrm{O}_{2}^{-\bullet}+2 \mathrm{H}^{+} \underset{\mathrm{Cu}^{+2}, \mathrm{Zn}^{+2}}{\longrightarrow} \mathrm{H}_{2} \mathrm{O}_{2}+\mathrm{O}_{2}$

$2 \mathrm{H}_{2} \mathrm{O}_{2} \stackrel{\text { catalase }}{\longrightarrow} 2 \mathrm{H}_{2} \mathrm{O}+\mathrm{O}_{2}$

Muitas das reações radicalares prejudiciais in vivo são evitadas ou modificadas pela ação de agentes inibidores ou antioxidantes. Por exemplo, no caso de superóxidos, a enzima $S O D$ age como agente de defesa contra esta espécie, enquanto as enzimas catalase e peroxidase atuam sobre $\mathrm{H}_{2} \mathrm{O}_{2}$.

Há ainda a proteção não enzimática por pequenas moléculas, dentre as quais as mais utilizadas estão as vitaminas $\mathrm{E}$ ( $\alpha$-tocoferol) e C (ácido L-ascórbico). A vitamina E é uma molécula lipossolúvel e tende a se concentrar no interior das membranas, agindo sinergisticamente com ascorbato. Ambos os radicais tocoferol e hidroascorbil não são muito reativos inviabilizando o processo de lipoperoxidação ${ }^{3}$. Os carotenóides destacam-se também como agentes antioxidantes, dentre os quais a pró-vitamina A ( $\beta$-caroteno), pigmento responsável pela cor característica da cenoura, é o carotenóide mais abundante e de maior atividade. Estudos recentes indicam uma possível atividade anti-cancerígena do $\beta$-caroteno, sendo usado como corante e antioxidante em alimentos ${ }^{40}$. Especificamente, o $\beta$-caroteno exibe uma boa capacidade de captura de radicais livres somente a pressões parciais normais de oxigênio no ar, comumente encontrada na maior parte dos tecidos biológicos sob condições fisiológicas ${ }^{41}$. 


\section{RADICAIS LIVRES E AS ESPÉCIES REATIVAS DE OXIGÊNIO}

Define-se como radical livre toda espécie que possui um ou mais elétrons desemparelhados. O elétron livre, que caracteriza o radical livre, pode estar centrado em um átomo de hidrogênio, oxigênio, nitrogênio, carbono, enxofre ou átomos de metais de transição. Na natureza existem duas importantes substâncias que podem gerar radicais livres, o oxigênio no estado fundamental $\left(\mathrm{O}_{2}\right)$ e o óxido nítrico $(\mathrm{NO})$, que ocorre como poluente atmosférico, mas que também é sintetizado em diversas células e atualmente é identificado como o fator relaxante dependente do endotélio ${ }^{42-44}$ e um importante vasodilatador $^{45}$. Reações de importância bioquímica de monóxido de nitrogênio envolvem a formação de complexos nitrosílicos com heme-proteínas, compostos nitrosotiólicos (cisteína e glutationa) e de peroxinitrito. O peroxinitrito promove a oxidação de grupos tiólicos, em particular a glutationa, associado com o consumo de oxigênio e regulando sua ação radicalar nas células do organismo ${ }^{46-48}$.

Pelo fato da molécula de oxigênio ser um bi-radical (possuir dois elétrons livres nos orbitais $\mathrm{p}$ antiligantes), o oxigênio reage preferencialmente com moléculas de configuração eletrônica semelhante. Como a maioria das biomoléculas não são bi-radicais, possuindo grande número de ligações covalentes, o oxigênio fica impedido (por restrição de "spin") de reagir com as mesmas, evitando assim que alvos celulares importantes sejam lesados $^{36,37}$. No entanto, o oxigênio pode dar origem a diversas espécies reativas, seja por absorção de energia ou por transferência de elétrons. Na forma de oxigênio singlete a restrição de "spin" desaparece, conferindo-lhe um maior poder oxidante.

Uma outra via de formação de espécies reativas de oxigênio (EROs) - oxidantes de maior importância biológica - consiste na redução unieletrônica do oxigênio à água, na qual a entrada de 4 elétrons na molécula de oxigênio promove o aparecimento do radical superóxido $\left(\mathrm{O}_{2}^{-}\right)$, peróxido de hidrogênio $\left(\mathrm{H}_{2} \mathrm{O}_{2}\right)$ e do radical hidroxila $\left(\mathrm{OH}^{-}\right)$, intermediários parcialmente reduzidos do oxigênio molecular, conforme o esquema ${ }^{36}$ mostrado na Eq. 3:

$$
\mathrm{O}_{2} \longrightarrow \mathrm{O}_{2}{ }^{-\cdot} \longrightarrow \mathrm{H}_{2} \mathrm{O}_{2} \longrightarrow \mathrm{HO}^{-\cdot} \longrightarrow \mathrm{H}_{2} \mathrm{O}
$$

$\mathrm{O}$ principal problema é que o $\mathrm{H}_{2} \mathrm{O}_{2}$ atravessa facilmente as membranas celulares e ao receber mais um elétron, normalmente proveniente do ferro ou do cobre, origina o radical hidroxila. Este último é, entre as espécies radicalares conhecidas, uma das mais reativas, pois necessita somente de mais um elétron para se estabilizar. Estas espécies reativas de oxigênio para se estabilizarem devem doar ou receber elétrons de uma ou outra molécula, tornando esta última uma espécie também radicalar e a conseqüência disto é a oxidação dos fosfolipídios de membranas celulares e subcelulares, do DNA, e das proteínas ${ }^{49}$.

Portanto, a toxicidade do oxigênio, em praticamente todas as células aeróbias, decorre da formação de EROs que podem interagir com diversas biomoléculas, com o objetivo de se estabilizarem lesando diferentes estruturas celulares ${ }^{49,50}$. Em condições normais, a concentração destas espécies dentro das células é extremamente baixa pelo fato de existirem enzimas antioxidantes que as removem, ou impedem sua formação. Estes radicais tendem a ser eliminados do organismo pelo conjunto das enzimas glutationa peroxidase, glutationa redutase, superóxido dismutase e pela catalase ${ }^{51}$.

As principais fontes endógenas geradoras de espécies reativas de oxigênio incluem as mitocôndrias e a atividade de algumas enzimas como: xantina oxidase, citocromo P450oxidase, monoaminooxidases, as enzimas envolvidas na via de produção de prostaglandinas e tromboxanos e a NADPHoxidase da membrana plasmática de macrófagos, que produzem uma grande quantidade de EROs em resposta ao estímulo fagocitário 35,36

Assim, com o surgimento da teoria da toxicidade dos radicais livres de oxigênio por volta dos anos 60 , aumentou o interesse dos pesquisadores sobre a ação principal das peroxidases, que se constituem numa grande variedade de enzimas, cuja principal função é proporcionar a defesa essencial contra espécies ativadas de oxigênio formadas durante o processo metabólico normal, particularmente pelas células aeróbicas ${ }^{\mathbf{5 2 , 5 3}}$. Atualmente, o principal foco das pesquisas relacionadas aos radicais livres, é a caracterização das enzimas reguladoras e seus respectivos substratos referentes aos sistemas de defesa antioxidantes dentro de suas funções metabólicas.

\section{MÉTODOS PARA DETERMINAÇÃO DE GLUTATIONA ASSOCIADOS AO ESTRESSE OXIDATIVO}

A resistência de muitas células contra o estresse oxidativo está associada com elevados níveis intracelulares de glutationa em sua forma reduzida. $\mathrm{O}$ estresse oxidativo pode causar mudanças no estado redox da glutationa aumentando a liberação de glutationa oxidada (dissulfeto) no organismo. Assim, alguns estudos têm direcionado o interesse no monitoramento de glutationa em amostras biológicas com o propósito de estudar-se a patologia de algumas doenças relacionadas ao estresse oxidativo ${ }^{6}$.

Atualmente existem diferentes métodos analíticos utilizados na determinação de glutationa procurando correlacionar os níveis desse importante tripeptídeo e enzimas que fazem parte deste ciclo metabólico com o sistema antioxidante. $\mathrm{Na}$ avaliação do estresse oxidativo pode-se estudar as variações das concentrações das principais enzimas e substratos do ciclo catalítico da glutationa, porém esta não é uma tarefa simples, devido ao fato de haver muitas interações químicas entre estas espécies. Na prática o que se faz é tentar estabelecer algumas substâncias indicadoras associadas ao estresse oxidativo e, cujas concentrações no organismo, possam ser relevantes ao diagnóstico clínico.

Neste trabalho procurou-se relacionar diferentes metodologias analíticas empregadas particularmente na determinação de glutationa em sua forma reduzida, devido à importância fisiológica deste tripeptídeo na manutenção do metabolismo antioxidante.

Na literatura, os métodos mais empregados para determinação de glutationa são baseados em cromatografia líquida de alta eficiência (HPLC) com detecção espectrofluorimétrica ${ }^{53-59}$ ou eletroquímica $^{60-62}$. A maioria destes métodos cromatográficos envolvem a derivatização da glutationa com agentes seletivos para tióis entre os quais os mais usados são o $o$-ftaldialdeído (OPA) e o mono-bromobimano (m-BBr). Entretanto, tióis reagem não seletivamente com ambos os reagentes sendo necessário aplicar-se técnicas de separação para evitar ou minimizar possíveis interferências. Mais recentemente, tem aumentado o interesse em eletroforese capilar para análise de tióis com detecção feita por espectrofotometria UV a baixos comprimentos de onda ${ }^{63}$ e por fluorescência induzida por laser após derivatização da amostra ${ }^{64}$.

Os métodos oficiais ${ }^{65,66}$ aceitos para determinação de glutationa incluem a titulação iodimétrica e a polarografia empregando eletrodo gotejante de mercúrio, monitorando-se a oxidação do resíduo de cisteína presente na molécula de glutationa. Dependendo do tipo de matriz na qual a amostra é determinada, pode haver problemas de interferências devido a outras espécies com comportamento redox similar e assim, estes métodos são mais recomendados para o controle de pureza de glutationa em fármacos.

Alguns métodos espectroanalíticos também vêm sendo desenvolvidos na determinação de glutationa, onde a amostra é convertida ou em um complexo colorido empregando-se para isso substâncias cromogênicas ${ }^{67,68}$ ou por meio de adutos com propriedades espectrofluorimétricas ${ }^{69,70}$. Neste último caso, os agentes mais empregados na reação com a glutationa são o OPA e o m-BBr (Figura 2), muito utilizados em etapas de derivatização da amostra nos métodos cromatográficos. 


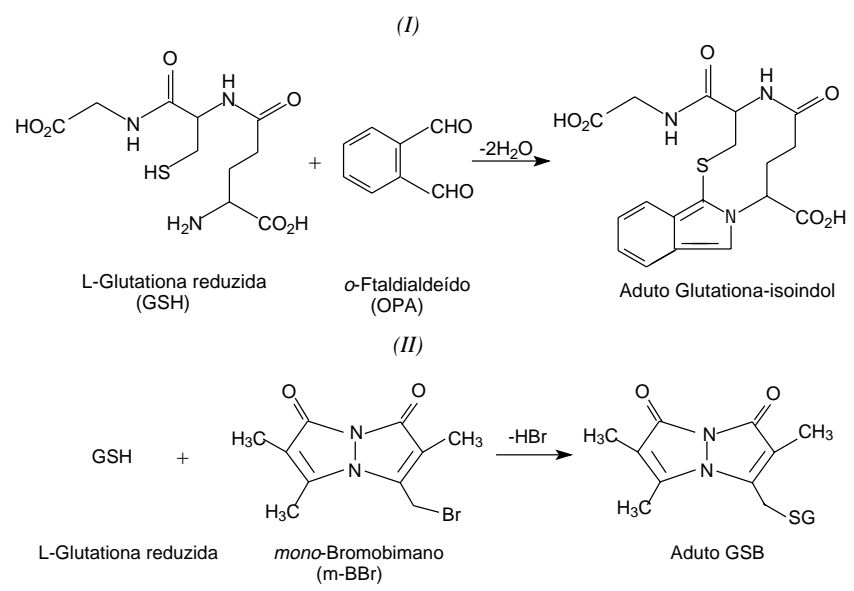

Figura 2. Esquemas de diferentes reações de derivatização para glutationa empregando reagentes seletivos para determinação espectrofluorimétrica de tióis: (I) OPA (II) $m-B B r$.

Os métodos eletroquímicos tradicionalmente têm encontrado importantes aplicações em análises de amostras e em sínteses orgânicas e inorgânicas. Neste sentido, a própria superfície do eletrodo de trabalho pode ser uma ferramenta muito útil em tais aplicações ${ }^{71,72}$. Alternativamente aos eletrodos convencionais tais como $\mathrm{Au}, \mathrm{Hg}$ e Pt, o carbono em suas diferentes formas é um sensor base preferido para verificar-se o comportamento redox de diferentes substâncias ${ }^{73,74}$. Fluidos biológicos são melhor analisados utilizando-se eletrodos de carbono quimicamente modifica$\operatorname{dos}^{75}$ e também eletrodos a base de pasta de carbono ${ }^{76,77}$. Recentemente, foi publicada uma importante revisão ${ }^{78}$ sobre eletrodos descartáveis fabricados pelo processo de "screen-printed" em eletroanalítica, descrevendo alguns sensores para glutationa.

Uma variedade de métodos eletroquímicos têm sido desenvolvidas para a detecção de glutationa. Assim, tem sido relatados na literatura métodos baseados em eletrodos de mercúrio ${ }^{79}$ como também a oxidação direta de glutationa (GSH) em eletrodos de carbono, porém com o inconveniente de potenciais de trabalho elevados ${ }^{80}$. No sentido de diminuir-se os potenciais na determinação eletroquímica direta de GSH, eletrodos de carbono quimicamente modificados com mediadores de elétrons têm sido avaliados, no intuito de minimizar possíveis interferentes principalmente em amostras biológicas. Um mediador de elétrons é uma substância de baixa massa molecular com propriedades redox que, numa primeira etapa, interage com o substrato ou produto de uma determinada reação e, então difunde-se até a superfície do eletrodo de trabalho, onde sofre uma transferência de elétrons rápida sob um potencial substancialmente menor àquele necessário para a eletrooxidação ou redução de um analito ${ }^{81}$.

Neste sentido, eletrodos de carbono quimicamente modificados com ftalocianina de cobalto ${ }^{82,83}$ foram empregados na eletrooxidação de GSH. GSH e cisteína foram eletrocataliticamente oxidadas em eletrodos de grafite modificados com tetraciano- $p$-quinodimetanotetrahidro-fulvaleno e 1,1-dimetilferroceno $^{84}$. Derivados de rutênio (III) ${ }^{85,86}$ também foram empregados em algumas determinações voltamétricas como mediadores de elétrons na detecção de tióis incluindo a glutationa.

Reações enzimáticas têm sido descritas tanto na determinação de glutationa como também de hidroperóxidos. Para exemplificar, algumas enzimas que foram usadas para tais análises incluem glutationa peroxidase ${ }^{87,88}$, "horseradish" peroxidase $^{89}$ e ciclooxigenase ${ }^{90}$. Citocromo $c^{91}$ e microperoxidase $e^{92}$ têm sido aplicadas na detecção de hidroperóxidos por quimiluminescência combinada com HPLC. Das enzimas citadas, glutationa peroxidase, que tem elevada seletividade para hidroperóxidos, tem sido empregada mais no intuito de determinar-se glutationa em matrizes biológicas de interesse clínico ${ }^{93}$.
Algumas reações redox de proteínas têm sido alvos de investigações eletroanalíticas utilizadas num esforço para tentar elucidar os mecanismos de transferência de elétrons ${ }^{94}$ e desenvolver novos biossensores eletroquímicos ${ }^{95,96}$. O mecanismo de transferência de elétrons heterogêneo tem sido estabelecido para algumas famílias de enzimas, entre estas para heme-proteínas e flavoenzimas ${ }^{97-99}$. De outra forma, poucos estudos eletroquímicos voltados para seleno-proteínas, como a glutationa peroxidase, têm sido apresentados para conseguir-se entender o mecanismo de bioeletrocatálise desta enzima ${ }^{15,100}$.

Como proposto na literatura ${ }^{100}$, o mecanismo catalítico da glutationa peroxidase envolve esta enzima no estado reduzido reagindo como selenolato (Ez-Se ${ }^{-}$) com o hidroperóxido, resultando em um derivado do ácido selênico. $\mathrm{O}$ hidroperóxido é reduzido ao álcool correspondente (Ez-SeOH) e em uma reação de duas etapas com glutationa (GSH) e através da forma selenossulfeto (Ez-SeSG), o selenol reduzido é regenerado, conforme o esquema mostrado na Figura 3.

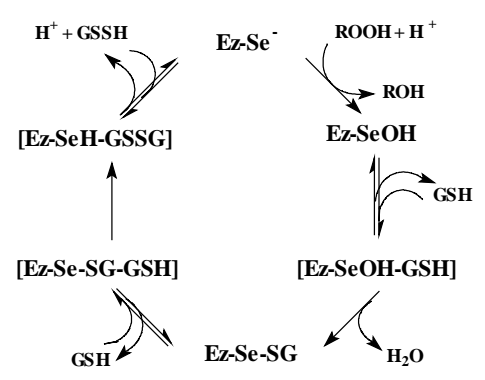

Figura 3. Mecanismo catalítico da seleno-enzima glutationa peroxidase sobre a glutationa em sua forma reduzida.

Entretanto, os vários estados de oxidação desta enzima durante o processo enzimático não foram conclusivamente identificados ${ }^{101}$.

Para fins analíticos, poucos sensores eletroquímicos para glutationa foram desenvolvidos até o momento, empregandose para isto um material biocatalítico imobilizado sobre um sensor base (biossensor) ou em reatores aplicados à sistemas de análise por injeção em fluxo (FIA).

Apenas um sensor potenciométrico usado na determinação enzimática de glutationa foi reportado na literatura ${ }^{102}$. Este método, utilizando a enzima glutationa transferase (GST), é baseado na capacidade desta enzima em promover a associação de glutationa (GSH) com metabólitos potencialmente perigosos para os seres vivos, permitindo assim a excreção destas substâncias nocivas à saúde. $\mathrm{O}$ substrato normalmente usado para detectar glutationa empregando esta técnica é o 1-cloro2,4-dinitrobenzeno, que se associa com GSH liberando em solução íons $\mathrm{H}^{+}$e $\mathrm{Cl}^{-}$, que podem ser monitorados indiretamente com o auxílio de eletrodos íon-seletivos (Figura 4).

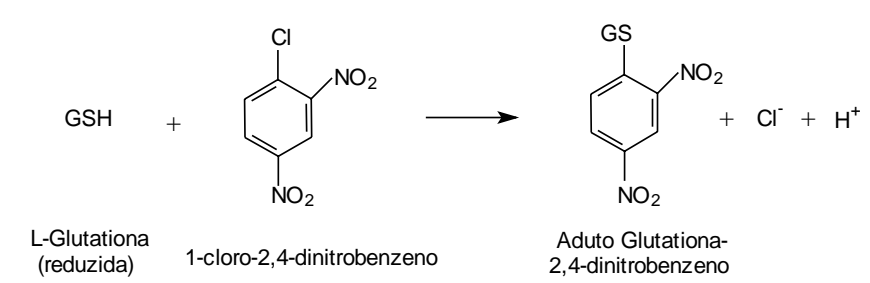

Figura 4. Reação utilizada na determinação potenciométrica de glutationa reduzida envolvendo 1-cloro-2,4-dinitrobenzeno e a enzima glutationa transferase.

Este método potenciométrico permite a detecção de glutationa em níveis de $1,0 \times 10^{-5}$ a $1,0 \times 10^{-1} \mathrm{~mol} \mathrm{~L}^{-1}$, com um coeficiente angular de Nernst de 52,0 $\mathrm{mV}$, mostrando-se como um 
método alternativo e simples na determinação de glutationa em amostras biológicas, porém com o inconveniente de se utilizar a enzima em sua forma solúvel e que, em muitos casos, não seria viável economicamente para análises clínicas rotineiras.

Mori et al. ${ }^{103}$ descrevem a determinação enzimática não de glutationa, mas de hidroperóxidos, envolvendo a imobilização de glutationa peroxidase com glutaraldeído e N-(2-aminoetil)3-aminopropila suportados em esferas de vidro ("glass beads"). Um sistema em fluxo com detecção espectrofotométrica é utilizado para monitorar-se diferentes hidroperóxidos como cosubstratos da glutationa, empregando-se como substância cromogênica o ácido 5,5'-ditio-bis-(2-nitrobenzóico), DTNB. A quantidade de hidroperóxidos é medida indiretamente pela diminuição da quantidade de GSH, avaliada pela diminuição da absorbância a $412 \mathrm{~nm}$, resultante da reação de glutationa com DTNB que gera o ácido 2-nitro-5-mercapto-benzóico (TNB) de coloração amarela (Figura 5).

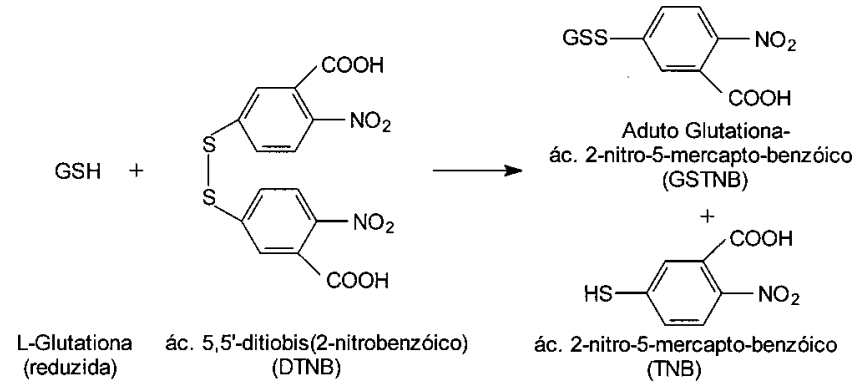

Figura 5. Reação entre glutationa reduzida e DTNB (reagente de Ellman) para a determinação de hidroperóxidos empregando a enzima glutationa peroxidase.

Alguns hidroperóxidos, comuns em amostras biológicas e associados com os sistemas de defesa antioxidantes do organismo, foram determinados por este método mostrando diferentes faixas lineares de calibração (Tabela 1), onde peróxido de hidrogênio, $t$-butil-hidroperóxido e cumeno-hidroperóxido apresentaram maior sensibilidade em relação a dois hidroperóxidos derivados de ácidos graxos, linoleato e linolenato. Os limites de detecção encontram-se na faixa de 0,2 a $0,5 \mathrm{nmol} \mathrm{L}^{-}$ 1 , exceto para metil-linolenato que apresentou baixa reatividade no processo enzimático.

Tabela 1. Faixas de resposta lineares e limites de detecção para alguns hidroperóxidos determinados espectrofotometricamente com glutationa peroxidase ${ }^{103}$.

\begin{tabular}{ccc}
\hline $\begin{array}{c}\text { Hidroperóxido } \\
(\mathrm{R}-\mathrm{OOH}) \\
\mathrm{R}=\end{array}$ & $\begin{array}{c}\text { Faixa linear } \\
\left(\mu \mathrm{mol} \mathrm{L} \mathrm{L}^{-1}\right)\end{array}$ & $\begin{array}{c}\text { Limite de } \\
\text { detecção } \\
\left(\mathrm{nmol} \mathrm{L}^{-1}\right)\end{array}$ \\
\hline $\begin{array}{c}\mathrm{H}- \\
t \text {-butil- }\end{array}$ & $6-100$ & 0,3 \\
Cumeno- & $4-100$ & 0,2 \\
Linoleato- & $6-100$ & 0,5 \\
Linolenato- & $6-100$ & 0,3 \\
Metil-linolenato- & $16-100$ & 0,3 \\
\hline
\end{tabular}

A quantificação de hidroperóxidos orgânicos pode ser também útil no diagnóstico de alguns processos de lipoperoxidação de membranas celulares, DNA e proteínas. Normalmente, os organismos vivos possuem mecanismos de defesa eficientes contra a ação de espécies reativas de oxigênio, porém toda vez que houver um desequilíbrio entre a produção de hidroperóxidos e os sistemas de defesa, estará estabelecido também um estresse oxidativo ${ }^{37}$.

\section{BIOSSENSORES PARA GLUTATIONA}

Os biossensores enzimáticos vêm sendo empregados em um grande número de determinações analíticas, principalmente em análises clínicas. A taxa de glicose, informação vital ao controle da diabete, é, sem dúvida, a principal aplicação comercial, embora outros dispositivos similares venham sendo usados para análise de uréia, ácido úrico, colesterol, oxalato, creatinina, lisina, lactato, e cisteína, entre os principais metabólitos, cuja concentração plasmática, tecidual ou urinária seja relevante ao diagnóstico clínico ${ }^{104,105}$.

No caso de glutationa, alguns biossensores foram desenvolvidos ao longo dos últimos anos utilizando diferentes sistemas transdutores (Tabela 2) associados a algumas técnicas de detecção analíticas.

Três metodologias baseadas na utilização de glutationa oxidase (GO) foram desenvolvidas para quantificação de glutationa, utilizando-se transdutores entalpimétricos ${ }^{106}$ e amperométricos ${ }^{107,108}$, nos quais a enzima foi adequadamente imobilizada. A enzima GO catalisa a reação de oxidação de GSH na presença de oxigênio molecular (Figura 1) produzindo glutationa na forma oxidada (GSSG) e peróxido de hidrogênio $\left(\mathrm{H}_{2} \mathrm{O}_{2}\right)$. Assim, a determinação de glutationa pode ser feita amperometricamente pela medida do consumo de oxigênio ou aumento de $\mathrm{H}_{2} \mathrm{O}_{2}$ em solução. No caso da técnica entalpimétrica uma segunda enzima, catalase, é empregada para a subsequente decomposição de $\mathrm{H}_{2} \mathrm{O}_{2}$ (reação exotérmica), podendo ser detectado pelo uso de um termístor.

Hua et al. ${ }^{109}$ descrevem a determinação enzimática de glutationa empregando glutationa peroxidase imobilizada sobre uma camada de resina perfluorada derivada de ácido sulfônico $\left(\right.$ Nafion $\left.{ }^{\circledR}\right)$ diretamente sobre eletrodo de carbono vítreo. Em pH 7, com uma camada de Nafion sobre o eletrodo sem a enzima, o pico de oxidação devido à GSH ocorre, mesmo com a adição de $\mathrm{H}_{2} \mathrm{O}_{2}$ à solução contendo GSH. Porém, quanto mais $\mathrm{H}_{2} \mathrm{O}_{2}$ é adicionado, um pico correspondente a este aparece $\mathrm{a}+0,88 \mathrm{~V}$ vs. eletrodo de calomelano saturado (ECS), enquanto o pico de GSH permanece constante. No caso do eletrodo contendo Nafion mais a enzima, o pico devido à GSH diminui drasticamente com a adição de $\mathrm{H}_{2} \mathrm{O}_{2}$ à solução e, com a adição de mais peróxido, o pico de GSH desaparece e começa a aparecer um pico de oxidação do próprio peróxido. Assim, os autores sugerem que esta reação enzimática, monitorada pelo consumo de peróxido de hidrogênio, pode ser um meio de se determinar indiretamente a concentração de GSH em solução, contribuindo ao mesmo tempo para um melhor entendimento do mecanismo de reação.

Mais recentemente dois biossensores para glutationa empregando ftalocianina de cobalto como mediador de elétrons foram desenvolvidos ${ }^{110,111}$. É possível observar (Tabela 2) a diminuição dos potenciais redox necessários à eletrocatálise de glutationa, podendo-se usar estes biossensores na análise de amostras mais complexas, devido à interferência causada pela presença de outras espécies eletroativas, quando presentes, a potenciais mais elevados.

\section{CONCLUSÕES E PERPECTIVAS FUTURAS}

As propriedades multifuncionais da glutationa estão refletidas num interesse crescente desta molécula como parte integrante de investigações às mais diversas, incluindo mecanismos enzimáticos de regulação antioxidante, biossíntese de macromoléculas, câncer, toxicidade devido à oxigenoterapia prolongada e mais recentemente associações com lesões oxidativas em DNA.

Um dos papéis do ciclo redox da glutationa e enzimas que compõe seu metabolismo é o de manter os níveis de hidroperóxidos lipídicos a níveis controlados, para evitar danos celulares provenientes do ataque desses radicais. 
Tabela 2. Dados comparativos mostrando diferentes sensores utilizando material biocatalítico imobilizado, empregados na determinação de glutationa nos últimos anos.

\begin{tabular}{|c|c|c|c|c|c|}
\hline Transdutor & $\begin{array}{l}\text { Método de imobilização } \\
\text { enzimática }\end{array}$ & $\begin{array}{l}\text { Faixa linear } \\
\left(\mathrm{mol} \mathrm{L}^{-1}\right)\end{array}$ & Amostra & $\begin{array}{l}\text { Estabilidade } \\
\quad \text { (dias) }\end{array}$ & Ref. \\
\hline Entalpimétrico & $\begin{array}{l}\text { - co-imobilização de } \\
\text { glutationa oxidase e } \\
\text { catalase com SAB }{ }^{\mathrm{a}} \text { sobre } \\
\text { oxirano-acrílico (Eupergit-C) } \\
\text { aplicado à FIA }{ }^{\mathrm{b}}\end{array}$ & $\begin{array}{l}5,0 \times 10^{-4} \mathrm{a} \\
1,0 \times 10^{-2}\end{array}$ & n.d. & 7 & 106 \\
\hline $\begin{array}{l}\text { Amperométrico } \\
(-0,68 \mathrm{~V} \text { vs. } \mathrm{Ag} / \mathrm{AgCl})\end{array}$ & $\begin{array}{l}\text { - imobilização covalente de } \\
\text { glutationa oxidase em } \\
\text { membrana de Immobilon-AV }{ }^{\circledR} \\
\text { sobre eletrodo de oxigênio } \\
\text { tipo Clark }\end{array}$ & $\begin{array}{l}1,0 \times 10^{-5} \mathrm{a} \\
1,0 \times 10^{-3}\end{array}$ & $\begin{array}{l}\text { Eritrócitos } \\
\text { hemolizados }\end{array}$ & n.d. & 108 \\
\hline $\begin{array}{l}\text { Voltamétrico } \\
\left(0,55 \mathrm{~V} \text { vs. } \mathrm{ECS}^{\mathrm{c}}\right)\end{array}$ & $\begin{array}{l}\text { - imobilização de glutationa } \\
\text { peroxidase em filme de Nafion }{ }^{\circledR} \\
\text { sobre eletrodo de carbono vítreo }\end{array}$ & n.d. & n.d. & n.d. & 109 \\
\hline $\begin{array}{l}\text { Amperométrico } \\
(0,25 \mathrm{~V} \text { vs. ECS })\end{array}$ & $\begin{array}{l}\text { - imobilização de glutationa } \\
\text { peroxidase em pasta de carbono } \\
\text { ("screen-printed") contendo } \\
\text { ftalocianina de cobalto } \\
\text { como mediador }\end{array}$ & $\begin{array}{l}1,0 \times 10^{-5} \mathrm{a} \\
5,0 \times 10^{-5}\end{array}$ & n.d. & 10 & 110 \\
\hline $\begin{array}{l}\text { Amperométrico } \\
(0,20 \mathrm{~V} \text { vs. ECS })\end{array}$ & $\begin{array}{l}\text { - imobilização de glutationa } \\
\text { peroxidase em eletrodo de } \\
\text { grafite - resina epóxi } \\
\text { ("screen-printed") contendo } \\
\text { ftalocianina de cobalto } \\
\text { como mediador }\end{array}$ & $\begin{array}{l}1,0 \times 10^{-6} \mathrm{a} \\
3,0 \times 10^{-5}\end{array}$ & n.d. & n.d. & 111 \\
\hline
\end{tabular}

${ }^{\mathrm{a}} \mathrm{SAB}$ - soro albumina bovina; ${ }^{\mathrm{b}}$ FIA - análise por injeção em fluxo; ${ }^{\mathrm{c}}$ ECS - eletrodo de calomelano saturado; n.d. - informação não disponível.

O processo de peroxidação lipídica pode causar modificações em alguns aminoácidos como triptofano, cisteína, histidina e tirosina, responsáveis pela formação de algumas proteínas, gerando doenças mutagênicas. O resíduo de triptofano quando atacado por espécies radicalares perde o grupamento aromático e consequentemente não participa mais no processo bioquímico normal.

Assim, o controle dos níveis de glutationa pode fornecer importantes informações bioquímicas do balanço oxidanteantioxidante no organismo, e ao mesmo tempo, permitir correlações clínico-laboratoriais com processos mutagênicos, nos quais a quantificação de glutationa como indicador dos níveis de processos de lipoperoxidação é associada com outros exames complementares como provas de função hepática e renal, onde são determinados importantes metabólitos como aspartato amino transferase, alanina amino transferase, fosfatase alcalina, uréia, creatinina, sódio e potássio, exames estes que traçam um perfil bioquímico mais amplo acerca de possíveis doenças associadas ao estresse oxidativo.

A determinação de glutationa neste contexto adquire particular atenção, onde os métodos analíticos usualmente empregados para tal fim vêm sendo desenvolvidos cada vez mais no sentido de se quantificar este substrato em matrizes complexas com elevada sensibilidade e baixos níveis de interferência, associados com a rapidez que análises rotineiras relacionadas ao diagnóstico clínico exigem.

O emprego de métodos eletroanalíticos no monitoramento de glutationa permite também estudar os mecanismos das reações redox que ocorrem entre este substrato e as enzimas que fazem parte deste ciclo, relacionando-os ao estresse oxidativo.
A utilização de biossensores pode, ao mesmo tempo, ajudar a entender os processos enzimáticos que ocorrem no organismo além de fornecer dados importantes com respeito aos níveis de glutationa na avaliação do sistema antioxidante.

\section{AGRADECIMENTOS}

Os autores agradecem à FAPESP (Fundação de Amparo à Pesquisa do Estado de São Paulo) pelo auxílio financeiro concedido.

\section{REFERÊNCIAS}

1. Di Ilio, C.; Sacchetta, P.; Angelucci, S.; Zezza, A.; Tenaglia, R.; Aceto, A.; Cancer Lett. 1995, 91, 19.

2. Saydam, N.; Kirb, A.; Demir, O.; Hazan, E.; Oto, O.; Saydam, O.; Guner, G.; Cancer Lett. 1997, 119, 13.

3. Meister, A.; Anderson, M. E.; Ann. Rev. Biochem. 1983, 52,711 .

4. Deneke, S.; Fanburg, B. L.; Am. J. Physiol. 1989, 257, L163.

5. Oberley, T. D.; Oberley, L. W.; Histol. Histopathol. 1997, 12,525 .

6. Navarro, J.; Obrador, E.; Carretero, J.; Petschen, I.; Aviñó, J.; Perez, P.; Estrela, J. M.; Free Rad. Biol. Med. 1999, 26, 410.

7. Hall, R.; Malia, R. G.; Medical Laboratory Hematology, Butterworths; London, 1986; p 294.

8. Burgunder, J. M.; Varriale, A.; Lauterburg, B. H.; Eur. J. Pharmacol. 1989, 36, 127.

9. Munthe, E.; Kass, E.; Jellum, E.; J. Rheumatol. 1981, 8, 14. 
10. Curello, S.; Ceconi, C.; Cargnoni, A.; Cornacchiari, A.; Ferrari, R.; Albertini, A.; Clin. Chem. 1987, 33, 1448.

11. Roederer, M.; Staal, F. J. T.; Raju, P. A.; Ela, S. W.; Herzenberg, L. A.; Proc. Natl. Acad. Sci. U.S.A. 1990, 87,4884

12. Mannervik, B.; Methods in Enzymology: Glutathione peroxidase; Academic Press, New York, 1985; Vol. 113; p 490

13. Carsol, M. A.; Pouliquen, I.; Giamarchi, P.; Lesgards, G.; Sergent, M.; Luu, R. P. T.; Analusis 1996, 24, 195.

14. Carsol, M. A.; Pouliquen, I.; Lesgards, G.; Marchis, G.; Puigserver, A.; Santimone, M.; Eur. J. Biochem. 1997 247, 248.

15. Lehmann, C.; Wollenberger, U.; Brigelius-Flohé, R.; Scheller, F. W.; J. Electroanal. Chem. 1998, 455, 259.

16. Mills, G. C.; J. Biol. Chem. 1957, 229, 189.

17. Cohen, G.; Hochstein, P.; Biochemistry 1963, 2, 1420.

18. Rotruck, J. T.; Pope, A. L.; Ganther, H. E.; Swanson, A. B.; Hafeman, D. G.; Hoekstra, W. G.; Science 1973, 179, 588.

19. Forstrom, J. W.; Zakowski, J. J.; Tappel, A. L.; Biochemistry 1978, 17, 2639.

20. Ip, C.; Hayes, C.; Budnick, R. M.; Ganther, H. E.; Cancer Res. 1991, 51, 595.

21. Foster, L. H.; Sumar, S.; Crit. Rev. Food Sci. Nutr. 1997, 37, 211.

22. Plecko, T.; Nordmann, S.; Rukgauer, M.; Kruse-Jarres, J. D.; Fresenius J. Anal. Chem. 1999, 363, 517.

23. Austin, L.; Arthur, H.; De Niese, M.; Gurusinghe, A.; Baker, M. S.; Anal. Biochem. 1988, 174, 575.

24. Smith, I. K.; Vierheller, T. L.; Thorne, C. A.; Anal. Biochem. 1988, 175, 408.

25. Eiríksdóttir, G.; Símonarson, B.; Biochem. Soc. Trans. 1989, 17, 702 .

26. Hawkes, W. C.; Craig, K. A.; Anal. Biochem. 1990, 186, 46.

27. Sentuerker, S.; Karahalil, B.; Inal, M.; Yilmaz, H.; Muesluemanoglu, H.; Gedikoglu, G.; Dizdaroglu, M.; FEBS Lett. 1997, 416, 286

28. McDonagh, M.; Ali, L.; Kahn, A.; Flatt, P. R.; Barnett, Y. A.; Barnett, C. R.; Biochem. Soc. Trans. 1997, 25, 146S

29. Mitchell, J. B.; Russo, A.; Br. J. Cancer 1987, 55, 96.

30. Meister, A.; Pharmacol. Ther. 1991, 51, 155.

31. Arai, M.; Imai, H.; Koumura, T.; Yoshida, M.; Emoto, K.; Umeda, M.; Chiba, N.; Nakagawa, Y.; J. Biol. Chem. 1999, 274, 4924.

32. Lipinski, L. J.; Höehr, N.; Mazur, S. J.; Dianov, G. L.; Senturker, S.; Dizdaroglu, M.; Bohr, V. A.; Nucl. Ac. Res. 1999, 27, 3153

33. Gutteridge, J. M. C.; Free Rad. Res. Comm. 1993, 19, 141

34. Rosen, G. M.; Pou, S.; Ramos, C. L.; Cohen, M. S.; Britigan, B. E.; FASEB J. 1995, 9, 200.

35. Blake, D.; Winyard, P. G.; Immunopharmacology of Free Radical Species, Academic Press, New York, 1995, p 301.

36. Halliwell, B.; Gutteridge, J. M .C.; Free Radicals in Biology and Medicine, Claredon Press, Oxford, 1991, p 543.

37. Sies, H.; Angew. Chem. Int. 1986, 25, 1058.

38. Sun, Y.; Free Rad. Biol. Med. 1990, 8, 583.

39. Wells, P. G.; Kim, P. M.; Laposa, R. R.; Nicol, C. J.; Parmana, T.; Winn, L. M.; Mutat. Res. 1997, 396, 65.

40. Burton, G. W.; Ingold, K. U.; Science 1984, 224, 569.

41. Cardoso, S. L.; Quim. Nova 1997, 20, 535.

42. Moncada, S.; Palmer, R. M. J.; Higgs, E. A.; Pharmacol. Rev. 1991, 43, 109.

43. Anderson, T. J.; Meredith, I. T.; Ganz, P.; Selwyn, A. P.; Yeung, A. C.; J. Am. Coll. Cardiol. 1994, 24, 555.

44. Dusting, G. J.; Macdonald, P. S.; Ann. Med. 1995, 27, 395

45. Ignarro, L. J.; Rev. Farm. Bioquim. Univ. S. Paulo 1998 , 34 (CO4), 3

46. Quijano, C.; Alvarez, B.; Gatti, R. M.; Augusto, O.; Radi, R.; Biochem. J. 1997, 322, 167.

47. Arteel, G. E.; Briviba, K.; Sies, H.; FEBS Lett. 1999, 445, 226.
48. Paglia, D. E.; Valentine, W. N.; J. Lab. Clin. Med. 1967, $70,158$.

49. Duran, N.; Cadenas, E.; Rev. Chem. Interm. 1987, 8, 147.

50. Greenwald, R.; Free Rad. Biol. Med. 1990, 8, 201.

51. MecCord, J. M.; Fridovich, I.; Biol. Chem. 1969, 244, 604. 52. Fridovich, I.; Adv. Enzymol. 1986, 58, 61.

53. Mansoor, M. A.; Svardal, A. M.; Ueland, P. M.; Anal. Biochem. 1992, 200, 218.

54. Yan, C. C.; Huxtable, R. J.; J. Chromatogr. B 1995, 672, 217.

55. Paroni, R.; De Vecchi, E.; Cighetti, G.; Arcelloni, C.; Fermo, I.; Grossi, A.; Bonini, P.; Clin. Chem. 1995, 41, 448.

56. Kok, R. J.; Visser, J.; Moolenaar, F.; De Zeeuw, D.; Meijer, D. K. F.; J. Chromatogr. B 1997, 693, 181.

57. Fukunaga, K.; Nakazono, N.; Yoshida, M.; Chromatographia 1998, 48, 690.

58. Parmentier, C.; Leroy, P.; Wellman, M.; Nicolas, A.; J. Chromatogr. B 1998, 719, 37.

59. Chen, X. P.; Cross, R. F.; Clark, A. G.; Baker, W. L.; Mikrochim. Acta 1999, 130, 225.

60. Halbert, K. H.; Baldwin, R. P.; J. Chromatogr. 1985, 345, 43.

61. Buchberger, W.; Winsawer, K.; Anal. Chim. Acta 1987, 196, 251.

62. How, W.; Wang, E.; Talanta 1991, 38, 557.

63. Piccoli, G.; Fiorani, M.; Biagiarelli, B.; Palma, F.; Potenza, L.; Amicucci, A.; Stocchi, V.; J. Chromatogr. A 1994, 676, 239.

64. Orwar, O.; Fishman, H. A.; Ziv, N. E.; Scheller, R. H.; Zare, R. N.; Anal. Chem. 1995, 67, 4261.

65. British Pharmacopæia, Her Majesty's Stationery Office, London, 1980; p 278.

66. The United States Pharmacopæia; The United States Pharmacopeial Convention, National Formulary XVI, Washington, DC, 21 ${ }^{\mathrm{a}}$ Ed., 1985; p 268.

67. Raggi, M. A.; Nobile, L.; Giovannini, A. G.; J. Pharmac. Biomed. Anal. 1991, 9, 1037.

68. Iwado, A.; Mifune, M.; Harada, R.; Mukuno, T.; Motohashi, N.; Saito, Y.; Anal. Sci. 1998, 14, 515.

69. Cohn, V. H.; Lyle, J.; Anal. Biochem. 1966, 14, 434.

70. Fahey, R. C.; Newton, G. L.; Dorian, R.; Kosower, E.M.; Anal. Biochem. 1981, 111, 357.

71. Murray, R. W.; Ewing, A. G.; Durst, R. A.; Anal. Chem. 1987, 59, 379A.

72. Gilmartin, M. A. T.; Hart, J. P.; Analyst 1995, 120, 1029.

73. Martorell, D.; Cespedes, F.; Martines-Fabregas, E.; Alegrat, E.; Anal. Chim. Acta 1994, 290, 343.

74. Koopal, C. G. J.; Bos, A. A. C. M.; Nolte, R. J. M.; Sens. Actuators B-Chem. 1994, 18, 166.

75. Wring, S. A.; Hart, J. P.; Analyst 1992, 117, 1215.

76. Kalcher, K.; Electroanalysis 1990, 2, 419.

77. Gorton. L.; Electroanalysis 1995, 7, 23.

78. Nascimento, V. B.; Angnes, L.; Quim. Nova 1998, 21, 614. 79. Allison, L. A.; Shoup, R. D.; Anal. Chem. 1983, 55, 8.

80. Wring, S. A.; Hart, J. P.; Birch, B. J.; Analyst 1989, $114,1563$.

81. Abruña, H. D.; Coord. Chem. Rev. 1988, 86, 135.

82. Wring, S. A.; Hart, J. P.; Birch, B. J.; Analyst 1989, 114, 1571.

83. Kinoshita, H.; Miya, T.; Kamihira, S.; Buns. Kagaku 1999, 48, 117

84. Kulys, J.; Drunggilens, A.; Anal. Chim. Acta 1991, 243, 287.

85. Cox, J. A.; Gray, T. J.; Electroanalysis 1990, 2, 107.

86. Nalini, B.; Narayanan, S. S.; Electroanalysis 1998, 10, 779.

87. Heath R. L.; Tappel, A. L.; Anal. Biochem. 1976, 76, 184.

88. Allen, K. G. D.; Huang. C. J.; Morin, C. L.; Anal. Biochem. 1990, 186, 108

89. Guilbault, G. G.; Brignac Jr., P.; Zimmer, M.; Anal. Chem. 1968, 40,190.

90. Yamagushi, T.; Agric. Biol. Chem. 1980, 44, 2747.

91. Marshall, P. J.; Warso, M.A.; Lands, W.E.M.; Anal. Biochem. 1985, 145, 192. 
92. Miyazawa, T.; Yasuda, K.; Fujimoto, K.; Anal. Lett. 1987, 20, 915 .

93. Yamamoto, Y.; Brodsky, M. H.; Baker, J. C.; Ames, B. N.; Anal. Biochem. 1987, 160, 7.

94. Dryhurst, G.; Kadish, K. M.; Scheller, F. W.; Renneberg, R.; Biological Electrochemistry, Academic Press, New York, 1982; Vol. 1; p 398.

95. Silva, L. R. D.; Gushikem, Y.; Kubota, L. T.; Coll. Surf. B-Biointerfaces 1996, 6, 309.

96. Rosatto, S. S.; Kubota, L. T.; Neto, G. O.; Anal. Chim. Acta 1999, 390, 65.

97. Ruzgas, T.; Csöregi, E.; Emnéus, J.; Gorton, L.; MarkoVarga, G.; Anal. Chim. Acta 1996, 330, 123.

98. Lindgren, A.; Emnéus. J.; Ruzgas, T.; Gorton, L.; MarkoVarga, G.; Anal. Chim. Acta 1997, 347, 51.

99. Belay. A.; Collins, A.; Ruzgas, T.; Kissinger, P. T.; Gorton, L.; Csöregi. E.; J. Pharmac. Biom. Anal. 1999, 19, 93.

100. Brigelius-Flohé, R.; In The Selenoprotein Glutathione Peroxidase; D. Dolphin, R. Poulson, O. Avramovic Eds.; Glutathione-Chemical, Biochemical, and Medical Aspects, Wiley, New York, 1989; p 643.
101. House, K. L; Dunlap, R. B.; Odom, J. D.; Wu, Z. P.; Hilvert, D.; J. Am. Chem. Soc. 1992, 114, 8573.

102. Compagnone, D.; Massoud, R.; Di Ilio, C.; Federici, G.; Anal. Lett. 1991, 24, 993.

103. Mori, H.; Kogure, M.; Kumabe, K.; Anal. Lett. 1992, $25,1643$.

104. Neto, G. O.; Yamanaka, H.; Quim. Nova 1988, 11, 432.

105. Fatibello-Filho, O.; Capelato, M. D.; Quim. Nova 1992, 15, 28.

106. Satoh, I.; Arakawa, S.; Okamoto, A.; Sens. Actuators BChem. 1991, 5, 245.

107. Satoh, I.; Arakawa, S.; Okamoto, A.; Anal. Chim. Acta 1988, 214, 415.

108. Compagnone, D.; Federici, G.; Scarciglia, L.; Palleschi, G.; Anal. Lett. 1994, 27, 15.

109. Hua, C.; Smyth, M. R.; O’Fagain, C.; Analyst 1991, 116, 929.

110. Wring, S. A.; Hart, J. P.; Birch, B. J.; Electroanalysis 1992, 4, 299.

111. Carsol, M. A.; Pouliquen, I.; Lesgards, G.; Macini, M.; Food Technol. Biotechnol. 1996, 34, 147. 